\title{
FAKTOR FISIK KIMIA LINGKUNGAN PENDUKUNG KEANEKARAGAMAN DAN KEMERATAAN HOLOTHUROIDEA PADA ZONA INTERTIDAL DESA HILA KECAMATAN KEPULAUAN ROMANG KABUPATEN MALUKU BARAT DAYA
}

\author{
Sriyanti I. A. Salmanu \\ Dosen Program Studi Pendidikan Biologi \\ E-mail: sriyanti_salmanu@yahoo.com
}

\begin{abstract}
Background: The sea is an ecosystem that has high biodiversity. Hila Village is one area that has a large enough waters located in the western part of Romang island, District of Romang Islands, Southwest Maluku District. Intertidal Zone Hila Village has different types of substrate, both muddy, sandy, sandy, dreamy, rocky, rocky, sandy, rocky, and rocky rocked. The existence of the types of sea cucumbers (Holothuroidea) in the coastal waters of Hila village quite a lot, physical chemical environmental factors in the coastal waters of Hila Village support the life of the sea cucumber.

Method: This research is descriptive research that reveal information about environmental characteristic (temperature, $\mathrm{pH}$, salinity, and dissolved oxygen), diversity and evenness of sea cucumber in intertidal zone of Hila Village.

Results: The results of the research on the intertidal zone of Hila Village, Pulau Romang Subdistrict, Southwest Maluku District, were found 7 genus and 8 spesies. The types of Holothuroidea found in the study sites are Bohadschia argus, Holothuria atra, Holothuria edulis, Bohadschia marmorata, Holothuria scraba, Chiridota violaceae, Holothuria fuscopunctata, and Opheodesoma spectabili. The Holothuroidea diversity index in the Intertidal Zone of Hila Village is 1.56, categorized by medium diversity, for evenly distributed evenness because the fairness index is 1.05 .

Conclusion: The index of the Holothuroidea diversity in the Intertidal Zone of Hila Village is 1.56, categorized by medium diversity, for evenly distributed evenness because the fairness index is 1.05 . Chemical Physical Factors The envelope found was the average temperature of $28.270 \mathrm{C}$, the average $\mathrm{pH} 6.373$, and the average salinity of $4.94 \%$, indicating that the Holothuroidea was able to adapt and live in the intertidal zone of Hila Village.
\end{abstract}

Keywords: diversity, evenness, Holothuroidea, intertidal zone.

\begin{abstract}
Abstrak
Latar Belakang: Laut merupakan suatu ekosistem yang memiliki keanekaragaman hayati yang tinggi. Desa Hila merupakan salah satu daerah yang memiliki perairan yang cukup luas yang terletak di bagian sebelah barat pulau Romang, Kecamatan Kepulauan Romang, Kabupaten Maluku Barat Daya. Zona intertidal Desa Hila memiliki berbagai jenis substrat yang berbeda, baik yang berlumpur, berpasir, berpasir berlamun, berlamun, berbatu, berpasir berbatu, berkarang, dan berbatu berkarang . Keberadaan jenis-jenis teripang (Holothuroidea) di perairan pantai desa Hila cukup banyak, faktor fisik kimia lingkungan pada perairan pantai Desa Hila Kecamatan Kepulaan Romang mendukung kehidupan dari teripang tersebut.

Metode: Penelitian ini bersifat penelitian deskriptif yaitu mengungkapkan informasi tentang karakterisitik lingkungan (suhu, $\mathrm{pH}$, Salinitas, dan oksigen terlarut), keanekaragaman dan kemerataan teripang pada zona intertidal Desa Hila Kecamatan Kepulauan Romang Kabupaten Maluku Barat Daya.

Hasil: Hasil penelitian pada zona intertidal Desa Hila Kecamatan Kepulauan Romang Kabupaten Maluku Barat Daya ditemukan 7 genus dan 8 spsesies. Jenis-jenis Holothuroidea yang di temukan di lokasi penelitian adalah Bohadschia argus, Holothuria atra, Holothuria edulis, Bohadschia marmorata, Holothuria scraba, Chiridota violaceae, Holothuria fuscopunctata, dan Opheodesoma spectabili. Indeks keanekaragaman Holothuroidea pada Zona Intertidal Desa Hila adalah 1,56, dikatagorikan keanekaragaman sedang, untuk kemerataannya relatif merata karena indeks kemerataannya adalah 1,05 .
\end{abstract}


Kesimpulan: Indeks keanekaragaman Holothuroidea pada Zona Intertidal Desa Hila adalah 1,56, dikatagorikan keanekaragaman sedang, untuk kemerataannya relatif merata karena indeks kemerataannya adalah 1,05. Faktor Fisik Kimia Lingkunan yang ditemukan adalah rata-rata suhu $28,27^{\circ} \mathrm{C}$, rata-rata $\mathrm{pH} 6,373$, dan rata-rata salinitas $4,94 \%$, hal ini mengindikasikan bahwa holothuroidea mampu beradaptasi dan hidup di zona intertidal Desa Hila.

Kata Kunci: keanekaragaman, kemerataan, Holothuroidea, zona intertidal.

\section{PENDAHULUAN}

Laut merupakan suatu ekosistem yang memiliki keanekaragaman hayati yang tinggi. Hampir setiap filum hewan dapat ditemukan di laut seperti, Coelentrata, Echinodermata, Annelida, serta Molluska. Dimanapun filum ini berada selalu dipengaruhi oleh faktor-faktor lingkungan seperti gerakan air, suhu, salinitas, dan cahaya (Romimohtarto dan Juwana, 2000). Salah satu jenis hewan yang hanya ditemukan di laut adalah kelas Holothuroidea (teripang) yang masuk pada filum Echidonemata.Teripang (Holothuroidea) merupakan golongan echinodermata yang paling umum dijumpai. Hewan ini banyak terdapat dipaparan terumbu karang, pantai berbatu atau berlumpur dan padang lamun. Hewan ini bergerak sangat lamban sehingga seakanakan teripang selalu dalam keadaan diam pada waktu kita lihat di alam bebas (Nontji, 1993). Kelangsungan hidup teripang (Holothuroidea) dipengaruhi oleh faktor fisik kimia perairan seperti suhu, $\mathrm{pH}$, salinitas, oksigen terlarut dan jenis substrat.

Desa Hila merupakan salah satu daerah yang memiliki perairan yang cukup luas yang terletak di bagian sebelah barat pulau Romang, Kecamatan Kepulauan Romang, Kabupaten Maluku Barat Daya. Zona intertidal Desa Hila memiliki berbagai jenis substrat yang berbeda, baik yang berlumpur, berpasir, berpasir berlamun, berlamun, berbatu, berpasir berbatu, berkarang, dan berbatu berkarang. Keberadaan jenis-jenis teripang (Holothuroidea) di perairan pantai desa Hila cukup banyak, faktor fisik kimia lingkungan pada perairan pantai Desa Hila Kecamatan Kepulaan Romang mendukung kehidupan dari teripang tersebut. Mengamati kenyataan tersebut maka penulis tertarik untuk faktor fisik kimia lingkungan pendukung keanekaragaman dan kemerataan teripang (Holothuroidea) yang berada di perairan pantai desa tersebut.

\section{MATERI DAN METODE PENELITIAN}

Penelitian ini bersifat penelitian deskriptif yaitu mengungkapkan informasi tentang karakterisitik lingkungan (suhu, $\mathrm{pH}$, Salinitas, dan oksigen terlarut), keanekaragaman dan kemerataan teripang pada zona intertidal Desa Hila Kecamatan Kepulauan Romang Kabupaten Maluku Barat Daya. Data yang diperoleh dianalisis secara deskriptif dengan sumber data sebagai berikut:

\section{Indeks Keanekaragaman (Shanon- Weiner)}

Rumus untuk menghitung indeks keanekaragaman spesies secara matematis dapat dirumuskan sebagai berikut:

$\mathbf{H}^{\prime}=-\Sigma\left(\frac{n i}{N}\right) \ln \left(\frac{n i}{N}\right)$

Keterangan:

$\mathrm{H}^{\prime}=$ Indeks diversitas ShannonWienner

$\mathrm{Ni}=$ Jumlah individu dari spesies ke-i

$\mathrm{N} \quad=$ Jumlah total individu

\section{Indeks Kemerataan (Evenness)}

Untuk menghitung kemerataan

Jenis menggunakan rumus sebagai berikut:

$$
\mathbf{E}=\frac{H^{\prime}}{\ln S}
$$

Keterangan:

$\mathrm{E} \quad=$ Indeks Kemerataan Jenis

$\mathrm{H}^{\prime} \quad=$ Indeks Keragaman

$\mathrm{S}=$ Jumlah Spesies 


\section{HASIL DAN PEMBAHASAN}

Secara umum perairan pantai Desa Hila Kecamatan Kepulauan Romang Kabupaten Maluku Barat Daya berada disebelah barat pulau Romang Kecamatan Kepulauan Romang Kabupaten Maluku Barat Daya yang memiliki luas daratan \pm $17.500 \mathrm{~km}^{2}$ (Pemerintah Desa Hila Kecamatan Kepulauan Romang Kabupaten Maluku Barat Daya, 2015). Karena letak wilayahnya yang berada di sebelah barat pulau Romang maka lautan Desa Hila hanya mengalami musim barat yang berlangsung pada bulan Januari dan berakhir pada bulan Maret.

\section{Komposisi jenis Holothuroidea yang ditemukan di lokasi penelitian}

Hasil penelitian pada zona intertidal Desa Hila Kecamatan Kepulauan Romang Kabupaten Maluku Barat Daya ditemukan 7 genus dan 8 spsesies. Jenis-jenis Holothuroidea yang di temukan di lokasi penelitian adalah Bohadschia argus, Holothuria atra, Holothuria edulis, Bohadschia marmorata, Holothuria scraba, Chiridota violaceae, Holothuria fuscopunctata, dan Opheodesoma spectabili, data tersebut dapat dilihat pada tabel 1.

Table. 1. Komposisi Taksonomi Holothruidea yang Ditemukan pada zona intertidal Desa Hila Kecamatan Kepulauan Romang Kabupaten Maluku Barat Daya.

\begin{tabular}{|c|c|c|c|c|}
\hline Kelas & Ordo & Family & Genus & Spesies \\
\hline \multirow[t]{3}{*}{ Holothuroidea } & Aspidochirotida & Holothuriidae & $\begin{array}{l}\text { Bohadschia } \\
\text { Holothuria }\end{array}$ & $\begin{array}{l}\text { Bohadschia argus } \\
\text { Holothuria atra } \\
\text { Holothuria edulis }\end{array}$ \\
\hline & & Aspidochirota & $\begin{array}{l}\text { Bohadschia } \\
\text { Holothuria }\end{array}$ & $\begin{array}{l}\text { Bohadschia marmorata } \\
\text { Holothuria scraba }\end{array}$ \\
\hline & Apodida & $\begin{array}{l}\text { Chiridotidae } \\
\text { Synaptidae }\end{array}$ & $\begin{array}{l}\text { Chiridota } \\
\text { Holothuria } \\
\text { Opheodesoma }\end{array}$ & $\begin{array}{l}\text { Chiridota violaceae } \\
\text { Holothuria fuscopunctata } \\
\text { Opheodesoma } \\
\text { spectabilis }\end{array}$ \\
\hline
\end{tabular}

Berdasarkan komposisi taksonomi Holothruidea yang Ditemukan pada zona intertidal Desa Hila Kecamatan Kepulauan Romang Kabupaten Maluku Barat Daya.
Pada kelas Holothruidea terdapat 2 ordo dengan 4 famili, 7 genus dan 9 spesies.

Untuk rekaman data hasil temuan Holothuroidea setiap transek dapat dilihat pada tabel 2.

Table 2. Jenis-Jenis Holothuroidea yang diperoleh Pada Zona Intertidal dengan di Desa Hila Kecamatan Kepulauan Romang Kabupaten Maluku Barat Daya.

\begin{tabular}{|c|c|c|c|c|c|}
\hline \multirow{2}{*}{ No } & \multirow{2}{*}{ Spesies Echinodermata } & \multicolumn{3}{|c|}{ Transek } & \multirow{2}{*}{ Jumlah } \\
\hline & & 1 & 2 & 3 & \\
\hline 1 & Bohadschia argus & - & 1 & 2 & 3 \\
\hline 2 & Holothuria atra & 1 & 1 & 2 & 4 \\
\hline 3 & Holothuria edulis & 1 & 2 & 3 & 6 \\
\hline 4 & Bohadschia marmorata & 1 & - & 1 & 2 \\
\hline 5 & Holothuria scraba & - & 1 & - & 1 \\
\hline 6 & Chiridota violaceae & - & 1 & 3 & 4 \\
\hline 7 & Holothuria fuscopunctata & - & - & 1 & 1 \\
\hline 8 & Opheodesoma spectabilis & 3 & 4 & 5 & 12 \\
\hline & Total & 6 & 10 & 17 & 33 \\
\hline
\end{tabular}

Darsono (2007) mengungkapkan bahwa di Indonesia terdapat 53 jenis teripang (Holothuroidea). Dari hasil temuan di lokasi penelitian jenis Holutroidea yang ditemukan hanya 8 spesies, dengan jumlah total 33 individu sehingga terlihat bahwa 
zona intertidal Desa Hila Kecamatan Kepulauan Romang memiliki jenis Holothuroidea yang sangat sedikit. Holothuroidea rentan dengan kodisi lingkungan dan hidup di tempat terlindung atau air tenang, di perairan pantai pada kubangan pasir dan dibalik batu atau memendam pada dasar lunak (Nontji, 2007). Kondisi zona intertidal Desa Hila Kecamatan Kepulauan Romang juga merupakan habitat yang cukup baik sebagai tempat hidup Holothuroidea karena memiliki jenis substrat berlumpur, berpasir, berlamun, berpasir berbatu, berbatu.

\section{Kondisi Faktor Fisik-Kimia Lingkungan Lokasi Penelitian}

Faktor fisik-kimia lingkungan yang diukur dalam penelitian ini adalah Suhu, $\mathrm{pH}$, Salinitas. Pengukuran faktor lingkungan dilakukan bersamaan dengan pengumpulan data jenis Holothuroidea di setiap plot pengamatan dan dimulai dari plot kesatu di daerah darat ke arah laut. Hasil pengukuran faktor fisik kimia lingkungan pada lokasi penelitian data selengkapnya dapat di lihat pada tabel 3.

Tabel 3. Hasil pengukuran Suhu, pH dan salinitas air laut pada 3 tarnsek zona intertidal di perairan Desa Hila Kecamatan Kepulauan Romang Kabupaten Maluku Barat Daya.

\begin{tabular}{cccc}
\hline Transek & $\begin{array}{c}\text { Rata -rata } \\
\text { suhu 5 plot }\end{array}$ & $\begin{array}{c}\text { Rata -rata } \\
\text { pH 5 plot }\end{array}$ & $\begin{array}{c}\text { Rata -rata } \\
\text { salinitas 5 plot }\end{array}$ \\
\hline I & $27,4^{\circ} \mathrm{C}$ & 6,35 & $4,88 \%$ \\
II & $28,2^{\circ} \mathrm{C}$ & 6,37 & $4,92 \% 0$ \\
III & $29,2^{\circ} \mathrm{C}$ & 6,4 & $5,02 \% 0$ \\
\hline Rata-rata & $\mathbf{2 8 , 2 7}$ & $\mathbf{6 , 3 7 3}$ & $\mathbf{4 . 9 4}$ \\
\hline
\end{tabular}

Menurut (Romimohtarto \& Juana, 2007) bahwa suhu alami air laut berkisar antara suhu dibawah $0^{\circ} \mathrm{C}-33^{\circ} \mathrm{C}$ dan perubahan suhu dapat memberi pengaruh besar terhadap sifat-sifat air laut dan termasuk biota laut. Nilai $\mathrm{pH}$ pada zona intetrtidal suatu perairan, sangat mempengaruhi keberadaan jenis Echinodermata. Kisaran $\mathrm{pH}$ normal untuk kehidupan suatu makhluk hidup pada zona intertidal berkisar antara 7,5-8,4 (Nybakken, 1992 dalam Rumahlatu, 2007). Ciri paling khas pada air laut adalah rasa asin, karena mengandung bermacammacam garam dan yang paling utama adalah $\mathrm{NaCl}$. Echinodermata mampu beradaptasi disalinitas 24,4 \%o sampai dengan 34,5 \%o (Pagett, 1981 dalam Rumahlatu, 2007).

Sesuai dengan hasil penelitian yang dilakukan, rata-rata suhu air laut pada ke 3 transek adalah $28,27^{\circ} \mathrm{C}$, rata-rata $\mathrm{pH}$ air laut pada ke 3 transek adalah 6,373, dan rata-rata salinitas air laut pada ke 3 transek adalah 4,94\%, maka holothuroidea sebagai salah satu hewan yang masuk dalam filum echinodermata juga dapat beradaptasi dan hidup di zona intertidal desa Hila Kecamatan Kepulauan Romang kabupaten Maluku Barat daya.

Indeks Keanekaragaman, Indeks Kemerataan, dan Indeks Kekayaan Jenis Holothuroidea pada Zona Intertidal diperairan Desa Hila.

Sesuai dengan hasil temuan yang diperoleh pada Zona Intertidal diperairan Desa Hila Kecamatan Kepulauan Romang Kabupaten Maluku Barat Daya, diperoleh indeks keanekaragaman ( $\left.\mathrm{H}^{\prime}\right)$ Holothuroidea adalah 1,56, indeks kemerataan (E) Holothuroidea adalah 1,05. Data selengkapnya dapat dilihat pada tabel 4. 
Tabel 5. Rekapitulasi Indeks Keanekaragaman dan Indeks Kemerataan Jenis Holothuroidea pada Zona Intertidal di perairan Desa Hila Transek I, II, dan III.

\begin{tabular}{|c|c|c|c|c|c|c|c|}
\hline \multirow{2}{*}{ No } & \multirow{2}{*}{ Spesies } & \multicolumn{3}{|c|}{$\mathrm{H}^{\prime}$} & \multicolumn{3}{|c|}{$\mathbf{E}$} \\
\hline & & T1 & T2 & T3 & T1 & T2 & T3 \\
\hline 1 & Bohadschia argus & 0 & 0.23 & 0.25 & 0 & 0.11 & 0.12 \\
\hline 2 & Holothuria atra & 0.30 & 0.23 & 0.25 & 0.14 & 0.11 & 0.12 \\
\hline 3 & Holothuria edulis & 0.30 & 0.32 & 0.31 & 0.14 & 0.15 & 0.15 \\
\hline 4 & Bohadschia marmorata & 0.30 & 0 & 0.17 & 0.14 & 0 & 0.08 \\
\hline 5 & Holothuria scraba & 0 & 0.23 & 0 & 0 & 0.11 & 0 \\
\hline 6 & Chiridota violaceae & 0 & 0.23 & 0.31 & 0 & 0.11 & 0.15 \\
\hline 7 & Holothuria fuscopunctata & 0 & 0 & 0.17 & 0 & 0 & 0.08 \\
\hline \multirow[t]{4}{*}{8} & Opheodesoma spectabilis & 0.35 & 0.37 & 0.36 & 0.17 & 0.18 & 0.74 \\
\hline & Jumlah & 1.25 & 1.61 & 1,82 & 0.95 & 0.77 & 1.44 \\
\hline & Total & \multicolumn{3}{|c|}{4,68} & \multicolumn{3}{|c|}{3,16} \\
\hline & Rata-rata & \multicolumn{3}{|c|}{$H^{\prime}=1.56$} & \multicolumn{3}{|c|}{$E=1.05$} \\
\hline
\end{tabular}

Suatu komunitas memiliki tingkat keragaman yang tinggi apabila nilai indeks Shannon 4,00 sedangkan tingkat keragaman sedang indeks Shannon adalah 1,00-3,00 dan tingkat keragaman rendah jika indeks Shannon adalah 0,00 (Odum, 1971 dalam Rumahlatu et al., 2008). Indeks keanekaragaman Holothuroidea pada Zona Intertidal Desa Hila Kecamatan Kepulauan Romang adalah 1,56, dikatagorikan keanekaragaman sedang. Sedangnya indeks keanekaragaman pada lokasi penelitian diakibatkan oleh sebagian substrat yang ditemukan adalah substrat berbatu yang bukan merupakan tempat hidup yang baik bagi Holothuroidea. Aktifitas yang dilakukan oleh masyarakat juga mempengaruhi rendahnya indeks keanekaragaman, salah satunya adalah bameti (kebiasaan mengambil biota laut di zona intertidal untuk dikonsumsi) yang dilakukan oleh masyarakat Desa Hila yang dilakukan terus menerus.

Fachrul (2007) mengungkapkan bahwa jika nilai kemerataan $E \approx 0$ maka kemerataan antar spesies rendah, artinya kemerataan individu yang dimiliki masingmasing spesies sangat jauh berbeda. Sedangkan jika $\mathrm{E}=1$, kemerataan antar spesies relatif merata atau jumlah spesies individu relatif sama. Dengan demikian, maka nilai kemerataan jenis Holothuroidea pada Zona Intertidal Desa Hila, dikatagorikan kemerataannya relatif merata karena indeks kemerataannya adalah 1,05. Meratanya jenis Holothuroidea disebabkan karena faktor fisik-kimia lingkungan yang mendukung penyebarannya (Krebs, 1989 dalam Rumahlatu, 2008).

\section{KESIMPULAN}

Indeks keanekaragaman Holothuroidea pada Zona Intertidal Desa Hila Kecamatan Kepulauan Romang adalah 1,56, dikatagorikan keanekaragaman sedang, untuk kemerataannya relatif merata karena indeks kemerataannya adalah 1,05. Faktor Fisik Kimia Lingkunan yang ditemukan adalah rata-rata suhu $28,27^{\circ} \mathrm{C}$, rata-rata $\mathrm{pH}$ 6,373 , dan rata-rata salinitas $4,94 \%$.

\section{DAFTAR PUSTAKA}

Darsono P, 2007. Teripang (Holothuroidea): Kekayaan alam dalam keragaman biota laut. Oseana xxxii, No. 2.

Fachrul. M. F. 2007. Metode Sampling Bioekologi. Jakarta. Bumi Aksara.

Nontji. A., 1993. Laut Nusantara. Jakarta. PT. Penerbit Djambatan.

Romimohtarto Kasijan dan Sri Juawana. 2007. Biologi Laut. Ilmu Pengetahuan Tentang Biota laut. Jakarta. PT. Penerbit Djambatan.

Rumahlatu, D. 2007. Hubungan antara Faktor Fisik-Kimia Lingkungan dengan Keanekaragaman dan Pola Distribusi Echinodermata pada Daerah Pasang Surut Kabupaten Seram Bagian Barat Sebagai Sumber Pembelajaran Ekologi Kelautan. Tesis. Tidak dipublikasikan. Malang: Jurusan Pendidikan Biologi, Program Pascasarjana Universitas Negeri Malang. 